\title{
Stroke MRIによる急性期脳虚血の診断と治療
}

\author{
宇野 昌明, 里見淳一郎 ${ }^{1}$, 鈴江 淳彦 ${ }^{1}$ \\ 中嶌 教夫 ${ }^{1}$, 佐藤 浩一 ${ }^{1}$, 永廣 信治 $^{1}$ \\ 米田 和英, ${ }^{2}$ 森田奈緒美, ${ }^{2}$ 原田 雅史 ${ }^{2}$
}

\section{Diagnosis and Treatment of Patients with Acute Cerebral Ischemia Using Stroke MRI}

\author{
Masaaki Uno, M.D., ${ }^{1}$ Junichiro Satomi, M.D. ${ }^{1}$ Atsuhiko Suzue, M.D., ${ }^{1}$ \\ Norio NaKa.Ima, M.D., ${ }^{1}$ Koichi Satoh, M.D., ${ }^{1}$ Shinji NagahiRo, M.D., ${ }^{1}$ \\ Kazuhide YonedA, M.D., ${ }^{2}$ Naomi Morita, M.D., ${ }^{2}$ and Masafumi Harada, M.D. ${ }^{2}$ \\ Department of ${ }^{1}$ Neurosurgery, and ${ }^{2}$ Radiology, School of Medicine, The University of \\ Tokushima, Tokushima, Japan
}

\begin{abstract}
Summary: Between November 1999 and September 2002, 175 patients with acute cerebral infarction were admitted to our Stroke Care Unit. Stroke MRI (Diffusion-, perfusion- and T2-weighted imaging and MR angiography) was performed for these patients, and we used diffusion/perfusion mismatch for indication of cardiovascular reconstruction. Of 175 patients, 44 were diagnosed as atherothrombotic infarction, 70 as cardioembolic infarction and 57 as lacunar infarction. In 19 patients (27.1\%) of cardioembolic infarction and 17 (38.6\%) of atherothrombotic infarction, cerebrovascular reconstructions were performed. Although outcome after treatment was good in only 3 of these 19 patients (15.8\%) with cardioembolism, outcome was good in 13 of 17 (76.5\%) with atherothrombotic infarction.

Outcomes of patients with cardioembolic internal carotid occlusion were very poor even if stroke MRI indicated acute thrombolysis, because almost all thrombolysis were failed. In conclusion, stroke MRI accurately diagnosed acute cerebral infarction, and acute and subacute cerebrovascular reconstruction induced good outcome in patients with atherothrombotic infarction.
\end{abstract}

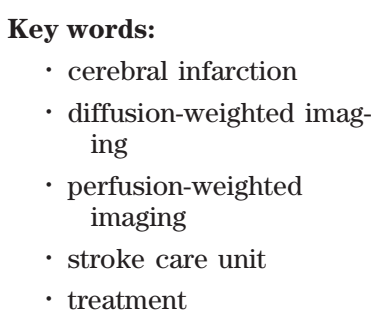

Surg Cereb Stroke (Jpn) 32: 262-266, 2004

\section{はじめに}

米国では脳卒中は心臓発作と同様に brain attack として 認識され, 発症からできるだけ早く脳卒中専門の施設に搬 送することを国民に啓蒙し，かつ国をあげてのキャンペー ンを展開している1). 本邦では必ずしも脳卒中の診断から
治療までがスムーズに施行されているとはいえず，急性期 治療の遅れが指摘されてきた ${ }^{515)}$. われわれは脳卒中急性 期の診断と治療を迅速かつ正確に行うために 1999 年 11 月 より stroke care unit(SCU)を開設した ${ }^{13)}$.今回 SCUに 入院した急性期脳卒中患者に対して，24時間体制で stroke MRIを施行し，脳卒中，特に脳梗塞の診断と治療

${ }^{1}$ 徳島大学 脳神経外科, ${ }^{2}$ 同 放射線科(受稿日 2003.8.7) 連絡先： $\overline{7} 770-8503$ 徳島市蔵本町 3丁目 18-15 徳島大学 脳神経外科 宇野昌明] [Mailing address: Masaaki Uno, M.D., Department of Neurosurgery, School of Medicine, The University of Tokushima, 3-18-15 Kuramoto-cho, Tokushima City, Tokushima 770-8503, Japan] 
成績について分析したので報告する.

\section{対象と方法}

1999 年 11 月より 2002 年 9 月までに当院の SCUに入院 した急性期脳卒中患者 295 例のうち, 脳虚血と診断した 175 例 (59.3\%) を対象とした。175例の脳梗塞の病態別症例 数はアテローム血栓性脳梗塞 44 例 (25.1\%), 心原性脳梗塞 70 例 (40\%)，ラクナ梗塞 57 例 (32.6\%)， その他 4 例 (2.3\%) であった。

\section{1. 脳梗塞の診断}

当院では脑卒中が疑われる急性期症例に対しては，くも 膜下出血が明らかに疑われる症例以外はまず緊急で stroke MRIを施行した。stroke MRI とは発症直後の stroke患者(出血を含む)に対して行い，頭部 CT 検査より， より敏感に病変を描出する目的で施行する MRI 検查のこ とで，当科で施行している内容は diffusion weighted imaging (DWI), perfusion-weighted MRI (PWI), T2weighted imaging (T2-MRI), MR angiography (MRA) で ある。各 MRIの撮像条件は他に報告しているので，ここ では省略する ${ }^{16)}$.

\section{2. 急性期脳虚血の治療方針}

ラクナ梗塞や大血管の閉塞性病変を伴わない心原性脳塞 栓やアテローム血栓性脳梗塞では抗凝固剂, 抗血小板療法, トロンボキサン合成阻害酵素 (カタクロット), エダラボ ンなどの投与による保存療法を行った。

stroke MRI上の MRA で主要血管に狭窄および閉塞が 認められ，DWI上での虚血巣と PWI 上での血流低下域の 差が大きい，すなわち DWI/PWI mismatchが大きい症例 に対しては急性期動脈内血栓溶解療法を考慮して, 緊急に 脳血管撮影を施行した。急性期動脈内血栓溶解療法の適応 は DWI/PWI mismatch が50\% 以上ある症例でかつ発症か ら 6 時間以内の症例とした ${ }^{16)}$. Fig. 1 に保存療法群と急性 期動脈内血栓溶解療法を行った群の代表例を呈示する.

発症から stroke MRI までの時間は脳塞栓が中間値 3 時 間，平均值 11.6 時間，アテローム血栓性脳梗塞が中間值 6 時間, 平均值 20.1 時間, ラクナ梗塞が中間値 19 時間, 平 均值 29.1 時間であった。

\section{結 果}

\section{1. 脳塞栓の治療方法と成績}

脳塞栓症例の 70 例の治療方法を血管閉塞部位別に検討 した (Fig. 2)。前述の動脈内血栓溶解療法の適応に沿って 内頸動脈閉塞に 7 例，中大脳動脈閉塞に対して 10 例，脳 底動脈閉塞に 2 例で，合計 19 例 (27.1\%)に対して施行した。
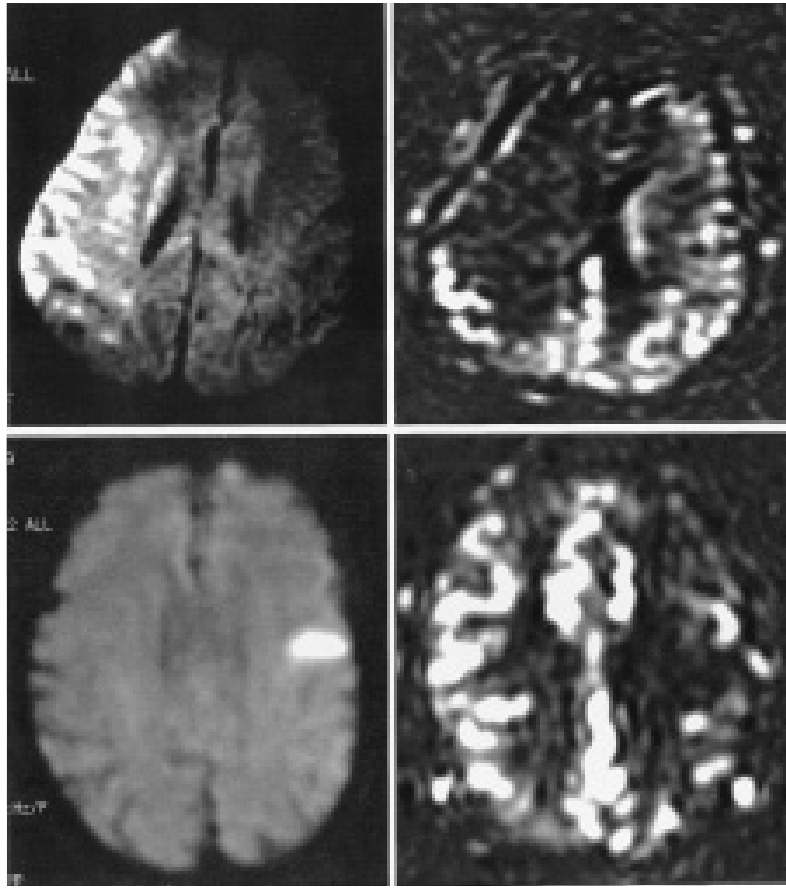

Fig. 1 Indication of acute reconstruction for patients with cerebral infarction using stroke MRI.

$\mathrm{A}$ and $\mathrm{B}$ : DWI/PWI mismatch was small and this case was treated conservatively.

A $\mid$ B $\quad$ C and D: DWI/PWI mismatch was larger than 50\%,

$\bar{C}$ D therefore, intra-arterial thrombolysis was performed in this case.

DWI: diffusion-weighted imaging

PWI: perfusion-weighted imaging

しかし 19 例の成績は 3 例 (15.8\%)の みが Rankin scale (RS) 1，2であり，10例 (52.6\%) はRS 4 以下で予後不良で あった Fig. 3)。保存的に加療を行った 50 例のうち RS 1, 2 の症例は 29 例 (52.6\%) であったが， 10 例 (20\%) の症例は 予後不良であった (Fig. 3).

70 症例中，内頸動脈閉塞は 12 例であったが，このうち 9 例はRS 4 以下でかつ死亡は 7 例 (58.3\%) で予後不良であ った１例のみが動脈内血栓溶解療法で完全再開通し，自 然再開通した 1 例と合計 2 例のみがRS $2(16.7 \%)$ で退院し た.

\section{2. アテローム血栓性脳梗塞の治療方法と成績}

Fig. 4 にアテローム血栓性脳梗塞の閉塞血管部位別の治 療法を示す. 動脈内血栓溶解療法を 8 例で施行し, 急性期 CEA 2 例で，急性期の stent 挿入術を 1 例に施行した. また急性期を保存療法で乗り切った 2 例に浅側頭動脈 - 中 大脳動脈吻合術を施行し，4例にCEA，1例に椎骨動脈 総頸動脈置換術を施行した．合計で 17 例 (38.6\%) に血行再 建術を施行した。これらの治療成績を Fig. 5 に示す。急性 


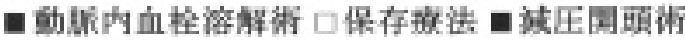

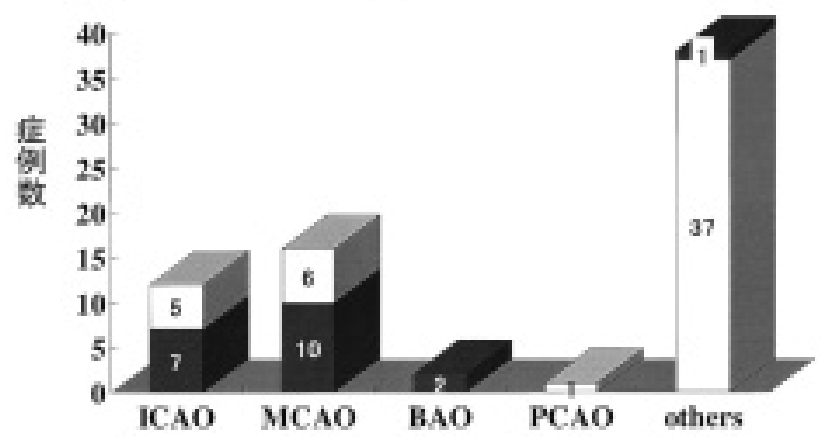

Fig. 2 Treatment of patients with cardioembolic infarction. ICAO: internal carotid artery occlusion, MCAO: middle cerebral artery occlusion, BAO: basilar artery occlusion, PCAO: posterior cerebral artery occlusion.

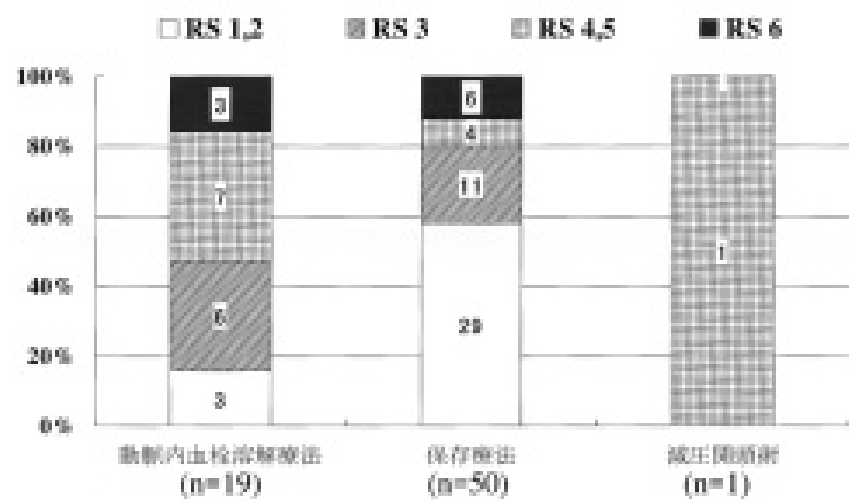

Fig. 3 Outcome of patients with cardioembolic infarction.

期血行再建を施行した 11 例の成績は 7 例 (63.6\%) は RS が 1，2であったが，2例 (18.2\%) は予後不良であった。慢性期 血行再建術を施行した 7 例中 6 例は予後良好であった。全 体では 13 例 $(72.2 \%)$ は予後良好で，これは脳塞栓例に比較 して有意に予後良好であった。保存療法を施行した 26 例 中 16 例 (61.5\%) は予後良好であった。

内頸動脈閉塞 10 症例中, RS 4 以下が 4 例で，このうち 死亡は 2 例 (20\%) であった。しかし動脈内血栓溶解療法を 施行して再開通した 2 例と, 急性期を保存療法で乗り切り, 慢性期に浅側頭動脈 - 中大脳動脈吻合術を施行した 1 例の 合計 3 例 (30\%) はRS 1 で退院した。

\section{3. ラクナ梗塞}

ラクナ梗塞と診断された 57 例は全例保存的加療がなさ れ，47例 (82.5\%) は RS = 1, 2 で退院した.

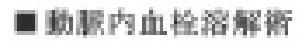

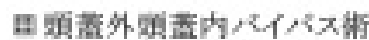

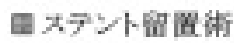

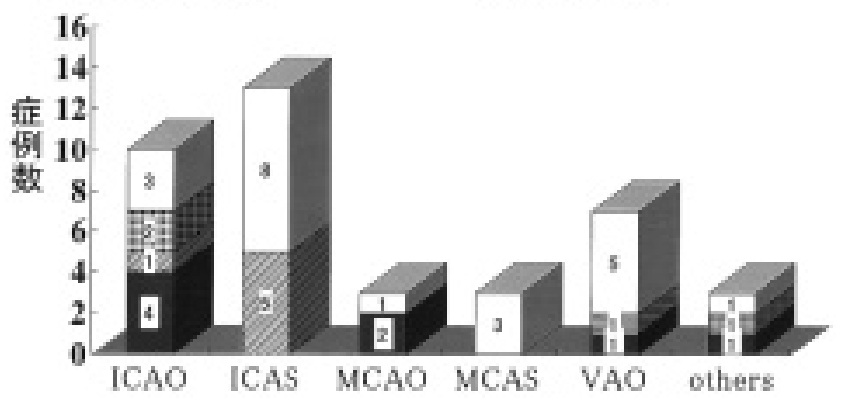

Fig. 4 Treatment of patients with atherothrombotic infarction. ICAO: internal carotid artery occlusion, ICAS: internal carotid artery stenosis, MCAO: middle cerebral artery occlusion, MCAS: middle cerebral artery stenosis,

VAO: vertebral artery occlusion

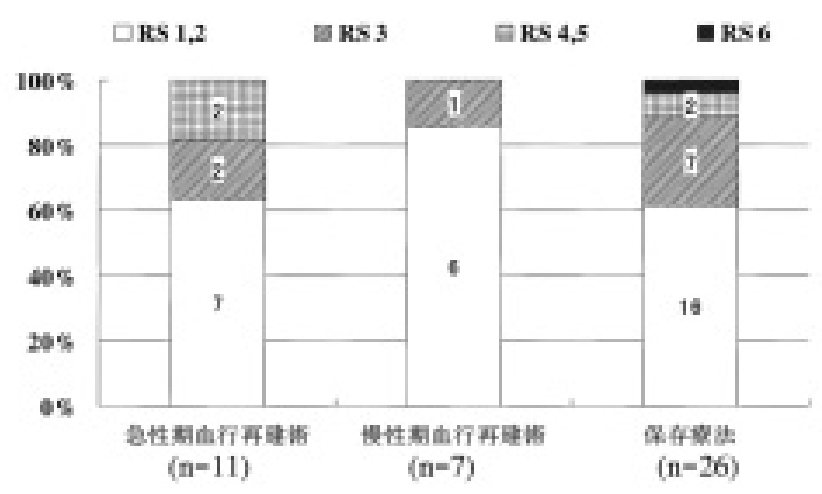

Fig. 5 Outcome of patients with atherothrombotic infarction.

\section{考察}

1990 年に Moseley らが猫の脳梗塞モデルでDWIが超急 性期の変化をとらえることを報告して以来 ${ }^{6)}, \mathrm{DWI}$ が脳 梗塞臨床診断に画期的な変化をもたらした ${ }^{2) 8)}$. 特に近年 超高速撮影 $(\mathrm{EPI})$ を施行できる臨床機が導入され, 日常臨 床でも DWIが施行できるようになった。われわれも 1996 年より DWI 臨床に取り入れ，1999年のSCU 開設以後 は放射線科の協力を得て，急性期脳卒中患者には 24 時間 体制でDWIを中心とした前述の stroke MRIを施行してき た。従来の頭部 CTのみの評価に比して，その診断価值は 飛躍的に向上し，正確な治療の選択や予後の予測が可能と なった。

\section{Stroke MRIの診断的価値}

動物実験ではDWIで脳虚血巣は数十分で出現すること 
が示された 。また人間でも発症後 39 分で脳虚血巣を認 めたことが報告され ${ }^{17)}$, 少なくとも発症から 1 時間前後 で，超急性期の虚血巣を示しうると考えられた。当初はこ の DWIで示された領域は可逆的変化の可能性があると考 えられたが，最近ではほとんどの症例で一度 hyperintensityを示した領域は最終的には脳梗塞に陥ることが示され た ${ }^{16)}$ 17). 1993 年に Robertsらが DWI と PWIを組み合わ せ，PWIでは血流低下を示しているが，DWI上は hyperintensityを示していない領域, すなわち penumbra 領域 を示す DWI/PWI mismatch を提唱した ${ }^{9)}$.この概念を臨 床で取り入れてDWI/PWI mismatchが大きなものに対し て血栓溶解療法を行うようになった ${ }^{8)}$ 16) 。この際に重要に なったのが大血管の閉塞性病変を示しうる MRA, すでに 時間的に発症から 6 時間以上経過した脳虚血を示す T2MRIを同時に施行することが重要となり, DWI, PWI, T2-MRI，MRA を急性期に一度に施行する stroke MRIの 概念が生まれた ${ }^{10)}$.われわれもこの概念を取り入れ，超 急性期の脳卒中患者に対して stroke MRIを施行してき た。

\section{Stroke MRI 導入後の治療戦略の変化とその成績}

stroke MRI 導入後, われわれはstroke MRIを最初に撮 影する方針で脳卒中を診断し, 治療してきた。もちろん, くも膜下出血が疑われる場合は頭部 CTをまず施行する が, 片麻痺などの巣症状を呈する症例は最初から stroke MRI を施行した。この中で MRA上, 内頸動脈, 中大脳動 脈, 椎骨動脈, 脳底動脈に狭窄や閉塞を認める場合はただ ちに脳血管撮影を施行し, 内頸動脈系では DWI/PWI mismatch を指標に, 椎骨・脳底動脈系ではDWIの虚血巣が 小さい症例に積極的に動脈内血栓溶解療法を行った。 stroke MRIが導入されるまでは頭部 CT T゙低吸収域が認 めらないものに対して動脈内血栓溶解療法が施行されてい たが，術後の出血の危険性が常に存在した. stroke MRI が施行され, 症例を限定することで術後の出血例は皆無と なった。また適応のない症例を MRIで判断できるように なり, 無駄な脳血管撮影が減少した。また従来の CTや T2-MRIではとらえられなかった脳幹の小さな病変も DWI で病巣を正確に診断できるようになった ${ }^{12)}$. 今後の課題 は椎骨脳底動脈系のPWIの測定精度が上昇し，この領域 の血行再建術の適応にも DWI/PWI mismatchが応用でき るかどうかであろう。

stroke MRIから適応を判断し, より積極的な治療を行 ったにもかかわらず，脳塞栓の治療成績は良好とはいえな かった ${ }^{4)}$. 特に内頸動脈閉塞症例はstroke MRIで血栓溶 解療法の適応があると判断し, 血栓溶解療法を施行したに もかかわらず，予後良好例は 2 例のみであった，今後はこ
の病態に対しては堅い血栓を破砕できる新たな治療法の開 発が必要となろう ${ }^{11)}$ 18)。これとは対照的にアテローム血 栓による狭窄や閉塞に対する血行再建術の予後は脳塞栓例 に比し良好であった. 同じ内頸動脈閉塞例でも急性期血行 再建術 11 例中 7 例が予後良好であったことより， DWI/PWI mismatch が大きな症例は積極的な治療が必要 であろう3) 14).

\section{Stroke MRIが取れる体制づくり}

われわれは放射線科の全面的な協力の下，24時間体制 でstroke MRIを施行している. 脳卒中患者が来院すると 日勤帯, 時間外でも20 分以内にはstroke MRIが施行でき るようになっている。米国心臓協会では MRIではなく, CTをまず施行しているが，患者到着から 25 分以内に頭部 CT を施行し，45分以内に読影を終了することを目標にし ている ${ }^{1)}$. 脳卒中の救急を積極的に行っている日本の 7 施 設での調査では，患者の来院から 1 時間以内に MRIが施 行された症例が約半数であり, その中央值は 90 分であっ た ${ }^{7)}$. 以上から放射線科の協力の下では脳卒中急性期の症 例でも患者到着から 1 時間以内には MRIが施行できるこ とが示されている. 今後はstroke MRI後の脳血管撮影, 動脈内血栓溶解術開始までの時間の短縮，あるいは静注用 t-PAの使用が日本で可能になれば治療成績の向上に結び つくと考えられる.

\section{文献}

1) American Heart Association: Part 7: The era of reperfusion: Section 2: Acute stroke. Circulation 102 [Suppl I]: I204-I-216, 2000

2) Arenillas JF, Rovira A, Molina CA, et al: Prediction of early neurological deterioration using diffusion- and perfusion weighted imaging in hyperacute middle cerebral artery ischemic stroke. Stroke 33: 2197-2205, 2002

3) Endo S, Kuwayama N, Hirashima Y, et al: Results of urgent thrombolysis in patients with major stroke and atherothrombotic occlusion of the cervical internal carotid artery. AJNR Am J Neuroradiol 19: 1169-1175, 1998

4) Jansen O, Kummer R, Forsting M, et al: Thrombolytic therapy in acute occusion of the intracranial internal carotid artery bifurcation. AJNR Am J Neuroradiol 16: 1977-1986, 1995

5）古賀政利, 木村和美, 峰松一夫, ほか：急性期脳卒中患者 の受診動向とその関連因子一大阪北部地区に扔ける検討一. 脳卒中 22: 301-306, 2000

6) Moseley ME, Cohen Y, Kucharczyk J, et al: Diffusionweighted MR imaging of anisotropic water diffusion in cat central nervous system. Radiology 176: 439-445, 1990

7）成富博章：厚生省科学研究費補助金 21 世紀型医療開拓促進 事業, 脳梗塞急性期の具体的な医療手順に関する調査研究. 平成 13 年度研究報告書, 2001

8) Neumann-Haefelin T, Wittsack H-J, Wenserski F, et al: Diffusion- and perfusion weighted MRI. The DWI/PWI mismatch region in acute stroke. Stroke 30: 1591-1597, 
1999

9) Roberts TP, Vexler Z, Derugin N, et al: High-speed MR imaging of ischemic brain injury following stenosis of the middle cerebral artery. J Cereb Blood Flow Metab 13: 940-946, 1993

10) Schellinger PD, Fiebach JB, Jansen O, et al: Stroke magnetic resonance imaging within 6 hours after onset of hyperacute cerebral ischemia. Ann Neurol 49: 460-469, 2001

11) Song JK, Cacayorin ED, Campbell MS, et al: Intracranial balloon angioplasty of acute terminal internal carotid artery occlusions. AJNR Am J Neuroradiol 21: 1308-1312, 2002

12) Toi H, Uno M, Harada M, et al: Diagnosis of acute brainstem infarction using diffusion-weighed MRI. Neuroradiology 45: 352-356, 2003

13）宇野昌明, 新野清人, 松原俊二, ほか：脳卒中医療の最前 線, 脳梗塞の急性期治療一Stroke Care Unitを中心として 一. 四国医学雑誌 56: 213-217, 2000
14) Uno M, Hamazaki F, Kohno $T$, et al: Combined therapeutic approach of intra-arterial thrombolysis and carotid endarterectomy in selected patients with acute thrombotic carotid occlusion. J Vasc Surg 34: 532-540, 2001

15）宇野昌明, 永廣信治：徳島県における脳梗塞急性期医療の 実態に関するアンケート調査. 脳卒中 23: 195-199, 2001

16) Uno $M$, Harada $M$, Yoneda $K$, et al: Can diffusion- and perfusion-weighted magnetic resonance imaging evaluated the efficacy of acute thrombolysis in patients with internal carotid artery or middle cerebral artery occlusion? Neurosurgery 50: 28-35, 2002

17) Yoneda $\mathrm{Y}$, Tokui K, Hanihara $\mathrm{T}$ et al: Diffusion-weighted magnetic resonance imaging: Detection of ischemic injury 39 minutes after onset in a stroke patients. Ann Neurol 45: 794-797, 1999

18) Zaidat OO, Suarez JI, Santillan C, et al: Response to intraarterial and combined intravenous and intra-arterial thrombolytic therapy in patients with distal internal carotid artery occlusion. Stroke 33: 1821-1827, 2002 